\section{Correspondence}

https://doi.org/10.11646/zootaxa.4323.3.13

http://zoobank.org/urn:Isid:zoobank.org:pub:1A2AABB3-9BDA-484D-8A19-A1FFD7647D6A

\title{
Taxonomic and nomenclatural acts formalizing the classification provided in the world catalogue of the Cleonini (Curculionidae: Lixinae)
}

\author{
MASSIMO MEREGALLI \\ Dept. Life Sciences and Systems Biology - University of Turin, Italy. Via Accademia Albertina 13, 10123 TORINO, ITALY. \\ E-mail: massimo.meregalli@unito.it
}

Several taxonomic and nomenclatural acts required to formalize the classification provided in the online World Catalogue of the Cleonini are proposed. The genera Epirrhynchus Schoenherr, 1826 and Nomimonyx Faust,1904 are excluded from the Lixinae: Cleonini and provisionally referred to the Cyclominae. Phaulosomus kilimanus Faust, 1904 is designated as type species of genus Phaulosomus Faust, 1904. The lectotype of Curculio nebulosus Linnaeus, 1758 is designated. New synonymies are proposed for 20 species, new combinations are proposed for 13 species, 11 species are resurrected from synonymy, 1 subspecies is resurrected from synonymy, 1 species is promoted to species rank from subspecies.

The World Catalogue of the Lixinae: Cleonini (WCC from here on) (Meregalli 2017) is available at http:// weevil.info/content/world-catalogue-curculionidae-lixinae-cleonini. Even though this online catalogue is not meant to be a taxonomic or phylogenetic revision of the tribe, during its preparation some taxonomic and nomenclatural changes were necessary to more properly accommodate some taxa. The formal taxonomic and nomenclatural acts to validate these changes are proposed in this paper. Since in the past several names had various interpretations, changes, for the Palaearctic taxa, refer to the classification provided in the Catalogue of the Palaearctic Coleoptera (CPC from here on; Meregalli \& Fremuth 2013 for Lixinae: Cleonini). For the extra-Palaearctic taxa, changes usually refer to the classification provided by Csiki (1934).

This paper corresponds to the "New nomenclatural and taxonomic acts" published in the CPC to formalize the nomenclatural changes there proposed. Therefore, no detailed discussion or illustrations are here added. The taxonomic and nomenclatural changes in the WCC were based usually on the examination of type specimens, or a critical reading of the descriptions. In the WCC photographs of almost all type specimens are provided, including those of the synonyms $(\mathrm{HT}=$ holotype; $\mathrm{PT}=$ paratype; $\mathrm{ST}=$ syntype; $\mathrm{LT}=$ lectotype $)$. Some additional remarks are made, when necessary, to better document the reasons behind the proposed changes.

\section{Taxa excluded from the Cleonini}

Epirrhynchus Schoenherr, 1826 transferred from Lixinae: Cleonini to Cyclominae.

Nomimonyx Faust, 1904 transferred from Lixinae: Cleonini to Cyclominae.

Remarks. These two closely related genera, or possibly a single genus, with three species [E. argus (Sparrmann, 1785), E. humerosus Faust, 1904 and N. perturbans Faust, 1904] from southern Africa have always been included in the Lixinae: Cleonini, based on their external morphology. However, they differ in the characters of the genitalia: the females do not posses the symbiont pouches associated with the gonocoxites, a synapomorphy of the Lixinae present in all species; moreover, the ovipositor, both gonocoxites and styli, as well as the male sternum VIII have completely different shapes from the Lixinae, and also from the Molytinae. They are provisionally referred to the Curculionidae: Cyclominae, pending research on their affinities. It should be added that these species have not been found since the end of the $19^{\text {th }}$ century. Specimens examined are often generically labeled "Cape Province" (or a similar expression, such as "Cap. b. Spe."), with the exception of two specimens of $N$. perturbans that are labeled "Riversdale" and two of $E$. humerosus respectively labeled "Port Elizabeth" and "Natal". It seems likely that most of their populations have been wiped out by human settlements and habitat destruction. 
Type species designations

Phaulosomus kilimanus Faust, 1904 here designated as type species of genus Phaulosomus Faust, 1904.

\section{Lectotype designations}

Curculio nebulosus Linnaeus, 1758. As illustrated by The Linnean Society (http://linnean-online.org/insects.html), seven specimens are labeled with this name. Four of them (LINN 7737, LINN 7738, LINN 7740 and LINN 7741) belong to the species currently named Coniocleonus nebulosus Linnaeus, 1758. The others are C. excoriatus (Gyllenhal, 1834) (LINN 7739), Pseudocleonus cinereus (Schrank, 1781) (LINN 7742) and Bothynoderes affinis (Schrank, 1781) (LINN 7743). The specimen labelled LINN 7737 is here designated as the Lectotype of Curculio nebulosus Linnaeus, 1758.

Other nomenclatural and taxonomic acts

Asproparthenis meridionalis (Chevrolat, 1873) transferred from synonymy with $A$. lusca (Chevrolat, 1869) to synonymy with Asproparthenis crotchi (Chevrolat, 1873) syn. n. (ST of each species examined, photographs in WCC).

Asproparthenis remaudierei (Hoffmann, 1962) resurrected as valid species, from synonymy with $A$. punctiventris (Germar, 1823) stat. res. (ST of A. remaudierei examined, photograph in WCC).

Atactogaster dejeani (Faust, 1904) synonym of Atactogaster paraleucosomus (Desbrochers des Loges, 1891) syn. $\mathbf{n}$. (based on description of $A$. paraleucosomus; ST of $A$. dejeani examined, photograph in WCC).

Bothynoderes karakumicus Bajtenov, 1981 synonym of Chromonotus (Faustius) menetriesi Faust, 1884 syn. n. (PT of B. karakumicus examined, photograph in WCC).

Bothynoderes richteri Voss, 1959 synonym of Chromonotus (Faustius) menetriesi Faust, 1884 syn. n. (HT of $B$. richteri examined, photograph in WCC).

Brachyrhinus granulatus Fischer von Waldheim, 1821 transferred to genus Chromosomus Motschulsky, 1860 as Chromosomus granulatus (Fischer von Waldheim, 1821) from genus Maximus Alonso-Zarazaga \& Lyal, 2009 comb. rev.

Cleonus fischeri Fåhraeus, 1842 synonym of Chromosomus granulatus (Fischer von Waldheim, 1821) syn. n.; consequently, Cleonus rugifer Motschulsky, 1845, formerly synonym of C. fischeri, is now synonym of Chromosomus granulatus syn. $\mathbf{n}$.

Maximus verrucosus (Gebler, 1829) resurrected as valid species from synonymy with Brachyrhinus granulatus Fischer von Waldheim, 1821 stat. res. (LT of M. verrucosus examined, photograph in WCC).

Remarks. Chromosomus fischeri (Fåhraeus, 1842) is a name currently used for a well-known species widespread in central Asia. However, it has a senior synonym, Brachyrhinus granulatus Fischer von Waldheim, 1821. The synonymy between $B$. granulatus and $C$. fischeri has been generally recognized, at least since Faust (1904: 208) but, for unknown reasons, the correct priority was never adopted. In CPC B. granulatus was erroneously referred to the genus Maximus, as the senior synonym of $M$. verrucosus.

Chromonotus (Chevrolatius) striolatus (Gebler, 1829) resurrected as valid species from synonymy with C. bipunctatus (Zoubkoff, 1829) stat. res. (LT of C. striolatus examined, photograph in WCC).

Chromonotus (Chromonotus) zaisanensis Legalov, 1999 synonym of Chromonotus (Chromonotus) beicki Günther, 1937 syn. n. (ST of $C$. beicki and PT of C. zaisanensis examined, photographs in WCC).

Cleonus bisignatus Roelofs, 1873 transferred to genus Atactogaster Faust, 1904 as synonym of Atactogaster inducens (Walker, 1859), as in Csiki (1934), from valid species in genus Cyphocleonus Motschulsky, 1860 as indicated by Egorov (1976) comb. rev., syn. rev. (ST of C. bisignatus examined, photograph in WCC).

Cleonus oculiventris Quedenfeldt, 1888, formerly considered species incertae sedis (Csiki 1934), transferred to genus Neocleonus Chevrolat, 1872 as synonym of Neocleonus maculipes (Gyllenhal, 1834) comb. n., syn. n. (ST of both species examined). 
Cleonus ovulum Quedenfeldt, 1888, formerly considered species incertae sedis (Csiki 1934), transferred to genus Calodemas Faust, 1904 as Calodemas ovulum (Quedenfeldt, 1888) comb. n. (based on description).

Coniocleonus (Coniocleonus) ferrugineus (Fåhraeus, 1842) resurrected as valid species from synonymy with $C$. alpinus (Gebler, 1833) stat. res. (ST of C. ferrugineus and LT of C. alpinus examined, photographs in WCC).

Coniocleonus alpinus (Gebler, 1833) and C. vinokurovi Ter-Minasyan \& Korotyaev, 1977, formerly in subgenus Angarocleonus Arzanov, 2006, referred to subgenus Coniocleonus (LT of C. alpinus and HT of C. vinokurovi examined, photographs in WCC).

Conorhynchus conirostris (Gebler, 1829) resurrected as valid species from synonymy with C. pulverulentus (Zubkov, 1829) stat. res. and $C$. pulverulentus (Zubkov, 1829) synonym of Conorhynchus conirostris (Gebler, 1829) syn. rev.

Remarks. The paper by Gebler (1829), formerly considered to have been published in 1830, and dated as such on the first page, actually appeared on October 4, 1829 (Schmitt 2017 and Alonso-Zarazaga, personal communication). The paper by Zubkov (1829) was surely printed after November 1, 1829 (date of the printing permit as reported on the second page). In the past, C. pulverulentus was considered a variety of C. conirostris. In 2013 Gebler's paper was thought having been published in 1830, and therefore in the CPC C. pulverulentus was used with priority over C. conirostris, but now the former use of $C$. conirostris has to be resurrected. A few other names in Cleonini are affected by this reversal of priority. However, in these cases Gebler's names were never used as valid (even at infraspecific rank). Therefore, pending further research on the possible application of Art. 23.9, or alternatively to propose the conservation of Zubkov's names to the International Commission on Zoological Nomenclature, the present day status is maintained (each case is indicated in WCC under the respective genus).

Cosmogaster (Arabocleonus) medvedevi Arzanov, 2009 synonym of Cosmogaster (Arabocleonus) dealbata (Germar, 1834) syn. n. (topotypical specimen of $A$. medvedevi examined, photograph in WCC).

Cosmogaster (Arabocleonus) dealbata venusta (Walker, 1871) synonym of Cosmogaster (Arabocleonus) dealbata (Germar, 1834) as (doubtfully) in Csiki (1934) syn. rev. (topotypical specimen of C. dealbata venusta examined, photograph in WCC).

Curculio omogeron Herbst, 1797 valid species in genus Xanthochelus Chevrolat, 1872, from homonym of $C$. omogeron Lichtenstein, 1796. The latter name was published in a paper that has been suppressed for nomenclatural purposes (Opinion 1820 by the International Commission on Zoological Nomenclature). As a consequence, since Art. 23.9 cannot be applied, Xanthochelus ewersmanni (Fåhraeus, 1842) becomes a synonym of Xanthochelus omogeron (Herbst, 1797) syn. n.

Entymetopus (Sforzia) pilosus (Chevrolat, 1873) resurrected as valid species from synonymy with E. limis (Ménétriés, 1849 ) stat. res. (LT of E. pilosus examined, photograph in WCC).

Epexochus mongolicus Meregalli \& Talamelli, 2009 objective synonym of Epexochus consobrinus (Ter-Minasyan, 1972) syn. n.

Remarks. Ter-Minasyan (1972) used the name Leucochromus consobrinus Faust, 1904 for a specimen from Mongolia, that nevertheless she described and labeled as "holotype" of L. consobrinus Faust. Faust (1904) had used the name Leucochromus lehmanni var. consobrinus for specimens from Aulie Ata, in Kazakhstan, sympatric with the type form but characterized by the lighter colour (Faust 1904: 191-192). The name is therefore infrasubspecific. Faust indeed had combined Cleonus lehmanni Ménétriés, 1849 and its variety consobrinus twice, once in Leucochromus and the second time in Epilectus (= Epexochus) (Faust 1904: 208). During the preparation of his monograph he probably recognized that the species does not belong to Leucochromus, and recombined it in Epilectus, without deleting the entry in Leucochromus. The editor of the Deutsche Entomologische Zeitschrift, who managed the publication of Faust's work after his death, did not notice the double appearance of these names. In the catalogue of the species (Faust 1904: 265) lehmanni and its variety are only listed in Epilectus. Meregalli \& Talamelli (2009) erroneously considered Ter-Minasyan (1972) to have made Faust's name available for the population from Aulie Ata, according to Art. 45.6.4.1, and used TerMinasyan's specimen from Mongolia as the holotype of E. mongolicus Meregalli \& Talamelli, 2009. Indeed, according 
to Art. 45.5.1, Ter-Minasyan had validly, though inadvertently, described a new species as Leucochromus consobrinus Ter-Minasyan, 1972.

Gonocleonus amenokal (Peyerimhoff, 1931) upgraded to species rank from subspecies of G. insignis (Desbrochers des Loges, 1875) stat. prom. (ST of both species examined, photographs in WCC).

Gonocleonus angulatus Chevrolat, 1873 resurrected as valid species from synonymy with G. margaritiferus (Lucas, 1844) stat. res. and $\boldsymbol{G}$ furcifrons (Marseul, 1876) transferred from synonymy with G. margaritiferus to synonym with Gonocleonus angulatus syn. n. (ST of both G. angulatus and G. furcifrons examined, photographs in WCC).

Gonocleonus foveatus Faust, 1904 resurrected as valid species from synonymy with G. munieri (Bedel, 1875) stat. res. (ST of both species examined, photographs in WCC).

Gonocleonus multicostatus Chevrolat, 1876 transferred from synonymy with G. munieri (Bedel, 1875) to synonymy with Gonocleonus heros (Chevrolat, 1876) syn. n. (HT of G. multicostatus and ST of G. munieri examined, photograph in WCC).

Gonocleonus scabrithorax Desbrochers des Loges, 1898 transferred to genus Coniocleonus Motschulsky, 1860 as synonym of Coniocleonus (Plagiographus) variolosus (Wollaston, 1864) comb. n., syn. n. (based on description).

Maximus leucophaeus (Ménétriés, 1849) transferred to genus Asproparthenis Gozis, 1886 as Asproparthenis leucophaea (Ménétriés, 1849) comb. n. (ST examined, photograph in WCC).

Mecaspis caesimvirgata Arnol'di, 1956 transferred to genus Georginus Jakobson, 1913 as Georginus caesimvirgatus (Arnol'di, 1956) comb. n. (ST examined, photograph in WCC).

Mecaspis pallasii (Fåhraeus, 1842) transferred to genus Georginus as Georginus pallasii (Fåhraeus, 1842) comb. n. (ST examined, photograph in WCC).

Menecleonus anxius (Gyllenhal, 1834) transferred from synonymy with M. virgatus (Schoenherr, 1832) to synonymy with Menecleonus signaticollis (Gyllenhal, 1834) syn. n.

Menecleonus simplicirostris (Chevrolat, 1873) transferred from synonymy with M. virgatus (Schoenherr, 1832) to synonymy with Menecleonus signaticollis (Gyllenhal, 1834) syn. n. (ST of M. simplicirostris examined, photograph in WCC).

Remarks. Menecleonus signaticollis and M. anxius were both described from Persia, whereas M. virgatus was described from Caucasus. All specimens examined from Caucasus differ from those from Persia in the key-characters cited by Faust (1904) for the distinction between the two species. It seems thus that the two taxa are geographical allopatric vicariants.

Microcleonus sedakoffi (Boheman, 1842) synonym of Microcleonus panderi (Fischer von Waldheim, 1835), as in Csiki (1934) syn. rev. (ST of M. sedakoffi examined, photograph in WCC).

Neocleonus maculipes (Gyllenhal, 1834) resurrected as valid species from synonymy with N. sannio (Herbst, 1795) stat. res. (ST examined); N. coquereli Chevrolat, 1873, N. frater Chevrolat, 1873, N. sannio modestus Faust, $1904, N$. sordidus Chevrolat, 1873, N. subsignatus (Walker, 1871) transferred from synonymy with $N$. sannio to synonymy with Neocleonus maculipes syn. n. (based on types or type locality, photographs in WCC).

Neocleonus sannio ripicola Voss,1962 synonym of Atactogaster affixa (Faust, 1894) syn. n. (HT of $N$. sannio ripicola and ST of $A$. affixa examined).

Neocleonus trifasciatus Chevrolat, 1873, formerly considered synonym of Neocleonus sannio (Csiki 1934), transferred to genus Calodemas Faust, 1904 as Calodemas trifasciatum (Chevrolat, 1873) valid species; comb. n., stat. res. (ST examined, photograph in WCC). 
Pachycerus blucheaui Fairmaire, 1898 transferred to genus Centrocleonus Chevrolat, 1872 as C. blucheaui (Fairmaire, 1898) comb. n. (ST examined, photograph in WCC).

Pachycerus granulatus (Olivier, 1807) transferred to genus Prionorhinus Chevrolat, 1872 as P. granulatus (Olivier, 1807) comb. n. (ST examined, photograph in WCC).

Paraleucochromus Obst, 1908 synonym of Stephanocleonus Motschulsky, 1860 syn. n.; consequently, $\boldsymbol{P}$. pleurocleonoides Obst, 1908 transferred to genus Stephanocleonus as Stephanocleonus pleurocleonoides (Obst, 1908) comb. n.

Remarks. According to the description, the type of $P$. pleurocleonoides Obst, 1908 should be conserved at ZHMB. Unfortunately, it was not found there, so it is presumably lost, or mislabeled and thus not recognizable anymore. Hence, it was not possible to ascertain its precise identity, but, based on the description and the original drawing, there are no doubts that it belongs to the genus Stephanocleonus. It is probably a synonym of a Chinese species of Stephanocleonus, but in absence of the type no specific identification can be proposed.

Pseudocleonus (Pseudocleonus) theryi Hustache, 1931 synonym of Pseudocleonus parallelus Escalera, 1914, syn. n. (ST of $P$. theryi and HT of $P$. parallelus examined, photographs in WCC).

Pycnodactylopsis ephippium (Faust, 1904) resurrected to subspecies of Pycnodactylopsis tomentosa (Fåhraeus, 1842) from synonymy with $P$. tomentosa stat. res. (ST of $P$. ephippium examined, photograph in WCC).

Stephanocleonus acerbus Faust, 1904 transferred to genus Calodemas Faust, 1904 as Calodemas acerbus (Faust, 1904) comb. n. (ST examined, photograph in WCC).

Stephanocleonus nasutus Ballion, 1878, formerly considered species incertae sedis (Csiki 1934), reinstated in genus Stephanocleonus as Stephanocleonus (Stephanocleonus) nasutus Ballion, 1878 comb. rev. (based on description).

Stephanocleonus parshus Anderson, 1987 transferred to genus Coniocleonus Motschulsky, 1860 as Coniocleonus (Angarocleonus) parshus (Anderson, 1987) comb. n. (PT examined, photograph in WCC).

Stephanocleonus plumbeus Leconte, 1876 transferred to genus Coniocleonus as Coniocleonus (Angarocleonus) plumbeus (Leconte, 1876) comb. n. (based on description).

Temnorhinus rungsi (Hoffmann, 1938) resurrected as valid species from synonym of T. mixtus (Fabricius, 1792) stat. res. (ST of T. rungsi examined, photograph in WCC).

\section{Acknowledgements}

I wish to thank Miguel Angel Alonso-Zarazaga for comments on some nomenclatural acts, Hélène Perrin, who helped in understanding a problem of interpretation of Lixus inquinatus Olivier, 1807, and Chris Lyal for general comments during the preparation of the World Catalogue of the Cleonini and for checking the English of this note.

\section{References}

Csiki, E. (1934) Curculionidae: Subfam. Cleoninae. In: Schenkling, S. (Ed.), Coleopterorum Catalogus auspiciis et auxilio. Vol. 134. W. Junk, Berlin, pp. 1-152.

Egorov, A.B. (1976) A review of the fauna of weevils (Coleoptera, Curculionidae) of Primorye territory. Revue d'Entomologie de l'URSS, 60 (№ 4), 826-841.

Faust, J. (1904) Revision der Gruppe Cléonides vrais. Deutsche Entomologische Zeitschrift, 1904 (1), 177- 284. https://doi.org/10.1002/mmnd.48019040120

Gebler, F.A. von (1829) III. Bemerkungen über die Insekten Sibiriens, vorzüglich des Altai. Allgemeine Bemerkungen über die im Kolywan-Woskresenskischen Hüttenbezirke vorkommenden Insekten. In: Ledebour, C.F. von, Reise durch das Altai-Gebirge und die soongorische Kirgisen-Steppe. Auf Kosten der Kaiserlichen Universität Dorpat unternommen im Jahre 1826 in Begleitung der Herren D. Carl Anton Meyer und D. Alexander von Bunge R. K. Collegien-Assessors. Zweiter Theil. G. Reimer, Berlin, pp. 1-228.

Meregalli, M. (2017) World Catalogue of the Curculionidae: Lixinae: Cleonini. In: Lyal, C.H.C. (Ed.), International Weevil Community Website. Available from: http://weevil.info/content/world-catalogue-curculionidae-lixinae-cleonini (accessed 16 
August 2017)

Meregalli, M. \& Fremuth, J. (2013) Curculionidae: Lixinae: Cleonini. In: Löbl, I. \& Smetana, A. (Eds.), Catalogue of Palaearctic Coleoptera. Vol. 8. Curculionoidea II. Brill, Leiden, pp. 437-456.

Meregalli, M. \& Talamelli, F. (2009) Revision of the genus Epexochus Reitter, with description of three new species (Coleoptera: Curculionidae: Lixinae: Cleonini). Zootaxa, 2011, 47-68.

Schmitt, M. (2017) Case 3725 - Lema decempunctata Gebler, 1829 (Insecta, Coleoptera, Chrysomelidae): proposed conservation of the emended specific name. Bulletin of Zoological Nomenclature, 74, 28-33.

https://doi.org/10.21805/bzn.v74.a009

Ter-Minasyan, M.E. (1972) Zhuki-dolgonosiki podsemejstva Cleoninae (Curculionidae, Coleoptera) sobrannje sovetsko-mongolskimi zoologicheskimi ekspeditsiami v 1967-1969. [Cleoninae (Coleoptera, Curculionidae) of the Soviet-Mongolian zoological expeditions, 1967-1969.] Nasekomye Mongolii, 1, 539-556. [Nauka, Leningrad]

Zubkov, B. (1829) Notice sur un nouveau genre et quelques nouvelles espèces de Coléoptères. Bulletin de la Société Impériale des Naturalistes de Moscou, 1 (6), 147-170, pls. 4-5. 